\title{
Comparison of early platelet activation in patients undergoing on-pump versus off-pump coronary artery bypass surgery
}

Andrea Ballotta, MD, FCCP, ${ }^{\mathrm{b}}$ Hisham Z. Saleh, MD, ${ }^{\mathrm{a}}$ Hisham W. El Baghdady, MD, ${ }^{\mathrm{b}}$ Magdi Gomaa, MD, ${ }^{\mathrm{a}}$ Federica Belloli, MD, ${ }^{\mathrm{b}}$ Hassan Kandil, MD, ${ }^{\mathrm{b}}$ Yahia Balbaa, MD, ${ }^{\mathrm{a}}$ Fabrizio Bettini, MD, Eduardo Bossone, MD, FCCP, FESC, ${ }^{\text {b }}$ Lorenzo Menicanti, MD, ${ }^{\text {b }}$ Alessandro Frigiola, MD, ${ }^{\mathrm{b}}$ Carmen Bellucci, MD, and Rajendra H. Mehta, MD, MS ${ }^{\mathrm{C}}$

From the Department of Cardio-thoracic Surgery, ${ }^{\text {a }}$ Cairo University, Cairo, Egypt; the Department of Cardiac Surgery and Critical Care, ${ }^{\text {b }}$ IRCCS Policlinico San Donato, San Donato Milanese, Milan, Italy; the Duke Clinical Research Institute, ${ }^{\mathrm{c}}$ Durham, NC.

Supported by the Cairo University Research Funds, Cairo, Egypt. Dr Mehta is funded by Duke Clinical Research Institute, Durham, NC.

Read in part at the National Congress of Italian Society of Cardiology, Florence, Italy, May 2006.

Received for publication Aug 28, 2006; revisions received Jan 22, 2007; accepted for publication Jan 29, 2007.

Address for reprints: Andrea Ballotta, MD, via Vittorio Emanuele, 37, Pizzighettone, 26026, Cremona, Italy (E-mail: andrea. ballotta@ libero.it).

J Thorac Cardiovasc Surg 2007;134:132-8

$0022-5223 / \$ 32.00$

Copyright (๑) 2007 by The American Association for Thoracic Surgery

doi:10.1016/j.jtcvs.2007.01.055
Objective: Cardiopulmonary bypass has been shown to be associated with platelet dysfunction, which has a potential for increasing the risk of perioperative bleeding. Off-pump coronary artery bypass surgery is thought to avoid this deleterious effect of pump use on platelets. However, the influence of off-pump coronary artery bypass surgery on platelets has not been thoroughly studied.

Methods: Accordingly, we evaluated 60 patients undergoing coronary artery bypass grafting prospectively using cardiopulmonary bypass and warm cardioplegic arrest $(\mathrm{n}=30)$ or an off-pump technique $(\mathrm{n}=30)$. Platelet function was evaluated before and 2 hours after coronary artery bypass grafting.

Results: Among patients undergoing on-pump coronary artery bypass surgery, all studies of platelet function were significantly abnormal after surgical intervention compared with results before surgical intervention. Similarly, among patients undergoing off-pump coronary artery bypass surgery, evidence of platelet dysfunction after surgical intervention was noted, with a lower platelet count and a higher proportion of P-selectin- and Annexin V-positive platelets. However, compared with the preprocedural value, the postprocedural decrease in platelet count $(78,200$ $\times 10^{3} / \mu \mathrm{L}$ vs $\left.103,000 \times 10^{3} / \mu \mathrm{L}\right)$ and platelet aggregation ( $0.8 \%$ vs $\left.10.9 \%\right)$ and increase in bleeding time ( 0 minutes vs +1.3 minutes), P-selectin-positive platelets (6.0\% vs $9.1 \%$ ), and Annexin V-positive platelets (1.7\% vs $3.7 \%$ ) were significantly lower in the off-pump coronary artery bypass surgery group compared with those in the on-pump coronary artery bypass surgery group, respectively.

Conclusions: Early postoperative decrease in platelet count and increase in platelet activation occurs to a much lesser extent and does not alter bleeding time or adenosine diphosphate-induced platelet aggregation in patients undergoing offpump coronary artery bypass surgery. This lack of significant effects on platelets might in part account for the potential decreased risk in bleeding and for the preserved hemostasis seen in patients undergoing off-pump coronary artery bypass surgery compared with those undergoing on-pump coronary artery bypass grafting surgery.

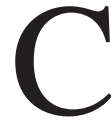
ardiopulmonary bypass has been shown to be associated with platelet dysfunction, which has a potential for increasing the risk of perioperative bleeding and thrombotic complications. ${ }^{1-5}$ By avoiding cardiopulmonary bypass, off-pump coronary artery bypass surgery (OPCAB) has been proposed to avoid this deleterious effect of pump use on platelets. ${ }^{6-9}$ This hypothesis remains attractive but unproved, because there is less information on the influence of $\mathrm{OPCAB}$ on postoperative platelet function. ${ }^{10,11}$ 


\section{Abbreviations and Acronyms \\ ACT = activated clotting time \\ $\mathrm{ADP}=$ adenosine diphosphate \\ $\mathrm{CABG}=$ coronary artery bypass grafting \\ $\mathrm{ONCAB}=$ on-pump coronary artery bypass surgery \\ $\mathrm{OPCAB}=$ off-pump coronary artery bypass surgery}

Accordingly, the purpose of this investigation was to evaluate the preoperative and early postoperative platelet function among patients undergoing $\mathrm{OPCAB}$, compared with that among patients undergoing on-pump coronary artery bypass surgery (ONCAB). We hypothesized that, in contrast to $\mathrm{ONCAB}$, in which exposure to nonendothelial surfaces of the pump results in a significant degree of platelet activation, $\mathrm{OPCAB}$ would have a potentially minor influence on platelet function.

\section{Materials and Methods}

We evaluated patients undergoing first-time coronary artery bypass grafting (CABG) at the Cardiothoracic Surgery Department, Cairo University Hospitals, between June 24, 2003, and July 10, 2004. We excluded patients with pre-existing coagulopathy or other disorders of hemostasis; those receiving aspirin, thienopyridines, or glycoprotein IIb-IIIa inhibitors in the last 10 days before the operation; those needing urgent or redo CABG; those needing concomitant valvular and left ventricular aneurysm operations; and those with hepatic or renal impairment. Findings on coronary angiography were used to guide the decision regarding the feasibility and safety of OPCAB and ONCAB. In this prospective, nonrandomized cohort study, a total of 60 consecutive patients who met the study criteria underwent either $\operatorname{OPCAB}(\mathrm{n}=30)$ or ONCAB $(\mathrm{n}=30)$. The study protocol was approved by the local institutional review board, and informed consent was obtained from all patients.

\section{Surgical Protocol}

All patients underwent operations through a full median sternotomy. The left internal thoracic artery was harvested in each patient with a conventional pleurotomy access. Additional conduits were obtained by harvesting the radial artery or segments of the great saphenous vein. No patients received perioperative antifibrinolytic drugs, and $325 \mathrm{mg} / \mathrm{d}$ aspirin was administered 6 hours after the procedure in both groups.

ONCAB technique. Cardiopulmonary bypass was instituted by using ascending aortic cannulation and 2-stage venous cannulation of the right atrium. A standard circuit was used: a Dideco tubing set, a Stockert roller pump, and a hollow-fiber membrane oxygenator (Sorin Biomedica, Midhurst, United Kingdom). The extracorporeal circuit was primed with $1500 \mathrm{~mL}$ of Hartmann's solution, $0.5 \mathrm{~g} / \mathrm{kg}$ mannitol, $10 \mathrm{~mL}$ of $10 \%$ calcium gluconate, and 10,000 IU of heparin. Nonpulsatile flow was used, and flow rates throughout bypass were $2.4 \mathrm{~L} \cdot \mathrm{m}^{-2} \cdot \mathrm{min}^{-1}$. Systemic temperature was kept between $32^{\circ} \mathrm{C}$ and $36^{\circ} \mathrm{C}$. Myocardial protection was achieved by using intermittent anterograde hyperkalemic warm blood cardioplegia. On completion of all distal anastomoses, the aortic crossclamp was removed, and the proximal anastomoses were performed with partial clamping. During cardiopulmonary bypass, when additional volume was required, this consisted of Hartmann's solution (provided the hematocrit level was greater than $22 \%$ ) or red blood cell concentrates (if the hematocrit level decreased to less than $22 \%$ ).

OPCAB technique. Folded gauze pads were put behind the heart to obtain proper exposure and to aid in stabilization. A stabilizer system (Octopus III; Medtronic, Inc, Minneapolis, Minn) was used for segmental stabilization of the myocardium adjoining the target vessels. Coronary arteries were occluded proximally and distally with silicone sutures. No drugs were administered to decrease the heart rate. An intracoronary shunt (Anastoflo Intravascular Shunt; Research Medical, Inc, Salt Lake City, Utah) was used only in case of relative electrocardiographic or hemodynamic instability or with excessive bleeding during the construction of the distal anastomosis. The proximal anastomoses were created with partial clamping of the aorta after completion of all distal anastomoses. Fluid administration was used together with increments of ephedrine to maintain the mean systemic pressure at 60 $\mathrm{mm} \mathrm{Hg}$ or greater during manipulation of the heart for construction of the distal anastomosis.

\section{Heparin and Protamine Management}

In both groups, heparin was administered before distal transection of the left internal thoracic artery. In the on-pump group heparin was given at a dose of $300 \mathrm{IU} / \mathrm{kg}$ to achieve a target activated clotting time (ACT) of 480 seconds or greater before commencement of CPB. The ACT, obtained with kaolin, was monitored during the bypass period (every 30 minutes), and an additional $5000 \mathrm{IU}$ of heparin was administered if required. In the off-pump group heparin $(150 \mathrm{IU} / \mathrm{kg})$ was administered to achieve an ACT of 250 to 350 seconds. On completion of all anastomoses, the heparin effect was reversed with protamine sulfate at a ratio of $1: 1$ in $\mathrm{CABG}$ cases and at a ratio of not greater than 0.5:1 in OPCAB cases. In ONCAB cases further doses of $50 \mathrm{mg}$ of protamine were administered when needed to obtain an ACT equal to or shorter than the baseline values.

\section{Blood Sampling}

Blood samples were obtained on 2 occasions: 1 day before the operation and 2 hours postoperatively in both groups of patients. Preoperative blood samples were collected by means of clean venipuncture with a 21-gauge butterfly infusion set with a minimal tourniquet. Samples obtained at 2 hours postoperatively were obtained from a central venous catheter (first $10 \mathrm{~mL}$ discarded). The first $3 \mathrm{~mL}$ of blood was collected in dipotassium ethylenediamine tetra-acetic acid vaccutainers. The next $4 \mathrm{~mL}$ of blood was collected in a polypropylene tube containing a one-tenth volume of $3.8 \%$ trisodium citrate.

\section{Hematologic Indices and Platelet Studies}

Hemoglobin values, hematocrit values, platelet counts, and mean platelet volume were measured with an automated blood analyzer (Coulter-STKS; Coulter Electronics, Inc, Hileah, Fla). The platelet counts were corrected for hemodilution. All determinations of prothrombin time and activated partial thromboplastin time vari- 
ables were performed with a fully automated coagulometer (STA4; Diagnostica Stago, Asnier sur Seine, France). Bleeding time was measured by using the Ivy method. Flow cytometry was used to determine the percentage of activated platelets expressing Annexin $\mathrm{V}$ and P-selectin by using the Coulter XL-MLC flow cytometer (Coulter Electronics, Inc). Platelet aggregation was performed with $10 \mu \mathrm{m}$ of adenosine diphosphate (ADP)-stimulated platelet aggregometry (Chronolog Aggregometer; Chronolog Corporation, Haverton, $\mathrm{Pa})$.

\section{Flow Cytometry}

We measured P-selectin- and Annexin V-positive platelets as markers of platelet activity. P-selectin surface translocation is an expression of platelet activation caused by shear stress and is also referred to as GMP-140, platelet activation-dependent granule external membrane protein. Similarly, Annexin V binds to microparticles released by activated platelets. Five-microliter aliquots of platelet-rich plasma were added to polypropylene tubes preloaded with $45 \mu \mathrm{L}$ of phosphate-buffered saline and saturating concentrations of one of the fluorescent isothiocyanateconjugated monoclonal antibody probes (Mouse AntiHuman CD62P FITC; Serotec, Oxford, United Kingdom) for detection of activation with P-selectin. For detection of activation with Annexin $\mathrm{V}, 5 \mu \mathrm{L}$ of platelet-rich plasma was added to a tube containing $45 \mu \mathrm{L}$ of binding buffer (10 mM Hepes/ $\mathrm{NaOH}$ [pH 7.4], $140 \mathrm{mM} \mathrm{NaCl}$, and $2.5 \mathrm{mM} \mathrm{CaCl}_{2}$ ) and $10 \mu \mathrm{L}$ of Annexin $\mathrm{V}$ labeled with fluorescein isothiocyanate (Annexin V FITC ASSAY KIT, Serotec). Immunolabeling of platelets with monoclonal antibodies and Annexin V was performed with 1-color analysis by using flow cytometry. Nonspecific membrane immunofluorescence was determined by using isotype-matched control antibodies. Samples were incubated in the dark without stirring for 15 minutes at room temperature and then diluted with $1 \mathrm{~mL}$ of phosphate-buffered saline for samples containing the monoclonal antibodies for P-selectin and $1 \mathrm{~mL}$ of binding buffer for samples containing the Annexin V. Samples were analyzed by means of flow cytometry within 2 hours of collection. No fixative was used because the fixative might change platelet antigenicity or cause cell clumping. Platelet samples were analyzed with a Coulter XL-MLC flow cytometer (Coulter Electronics, Inc). The analyses were performed for 10,000 events in each sample. Logarithmic amplification was used for the fluorescence signals, and linear amplification was used for light-scattering signals. The platelet population was identified on the basis of the forward and sideways scattering characteristics. For the data analysis to determine the percentage of activated platelets, the threshold for platelet activation was set at the percentage of fluorescence-positive platelets in samples corrected for the percentage contributed by the nonspecific binding of isotype-matched control antibodies.

\section{Platelet Aggregation}

Platelet aggregation was performed with $10 \mu \mathrm{m}$ of ADP-stimulated platelet aggregometry (Chronolog Aggregometer; Chronolog Corporation) in platelet-rich plasma. Platelet-rich plasma was adjusted to a platelet count of approximately $250,000 / \mu \mathrm{L}$, and aggregation was measured at room temperature.
TABLE 1. Clinical characteristics of patients

\begin{tabular}{|c|c|c|c|}
\hline Characteristics & OРCAB group & ONCAB group & $P$ value \\
\hline $\mathrm{N}$ & 30 & 30 & \\
\hline Age (y), median (IOR) & $57(48-69)$ & $58(49-69)$ & NS \\
\hline Female sex & $8(26.7 \%)$ & $9(30 \%)$ & .77 \\
\hline $\begin{array}{l}\text { BMI }\left(\mathrm{kg} / \mathrm{m}^{2}\right) \text {, median } \\
\quad(\mathrm{IOR})\end{array}$ & $29.4(27-31.8)$ & $29.7(27-32)$ & NS \\
\hline \multicolumn{4}{|l|}{ NYHA class } \\
\hline I & $8(26.7 \%)$ & $6(20 \%)$ & .54 \\
\hline II & $22(73.3 \%)$ & $24(80 \%)$ & NS \\
\hline \multicolumn{4}{|l|}{ CCS grade } \\
\hline 2 & $21(70 \%)$ & $20(66.7 \%)$ & .78 \\
\hline 3 & $9(30 \%)$ & $10(33.3 \%)$ & NS \\
\hline $\begin{array}{c}\text { Hemoglobin }(\mathrm{g} / \mathrm{dL}), \\
\text { median }(\mathrm{IQR})\end{array}$ & $14.3(13.0-15.2)$ & $14.2(13.0-15.6)$ & NS \\
\hline Diabetes & $13(43.3 \%)$ & $10(33.3 \%)$ & .43 \\
\hline Hypertension & $11(36.7 \%)$ & $10(33.3 \%)$ & .79 \\
\hline Current Smokers & 16 & 15 & NS \\
\hline No. of diseased vessels & 4 & 4 & NS \\
\hline $\begin{array}{l}\text { Left ventricular ejection } \\
\text { fraction }(\%), \\
\text { median (IOR) }\end{array}$ & $51(45-58)$ & $50(43-58)$ & .92 \\
\hline
\end{tabular}

OPCAB, Off-pump coronary artery bypass surgery; ONCAB, on-pump coronary artery bypass surgery; $I Q R$, interquartile range; $B M I$, body mass index; NYHA, New York Heart Association; CCS, Canadian Cardiovascular Society.

\section{Statistical Analysis}

The data were collected by using a data collection format. Data are reported as medians with interquatile ranges, and analysis was done with SPSS version 12.0 software. The Wilcoxon signed-rank test was used to compare the difference (or change) in a numeric variable observed for 2 paired or matched groups and for beforeand-after measurements made on the same group of subjects, whereas the $\chi^{2}$ test was used for categoric variables.

\section{Results}

No substantial differences in baseline characteristics were observed between the 2 groups, as shown in Table 1. As a result of inherent difference between the 2 surgical techniques of coronary revascularization, the operative time was significantly longer for the ONCAB group compared with that for the OPCAB group. Similarly, heparin and protamine doses were significantly higher for the former cohort (Table 2). The need for packed red blood cell, fresh frozen plasma, or platelet transfusions was similar in the 2 groups (Table 3). No substantial differences in clinical outcomes were observed between the 2 cohorts (Table 3 ).

Table 4 shows the preoperative baseline studies of platelet function. The preoperative platelet count, platelet volume, bleeding time, and selectin- and Annexin V-positive circulating platelet count were similar in the 2 groups. Table 4 also demonstrates the influence of ONCAB and OPCAB on platelet function in the preoperative and postoperative 
TABLE 2. Operative characteristics of patients

\begin{tabular}{lccc}
\hline Operative characteristics & OPCAB group & ONCAB group & $\boldsymbol{P}$ value \\
\hline Operative time (min), median (IOR) & $205.5(180-230)$ & $268.0(240-284)$ & $75.0(60-85)$ \\
CPB time (min), median (IOR) & - & $51.3(30-70)$ & .0001 \\
Aortic crossclamp time (min), median (IOR) & $2.7(2-3)$ & $2.9(2-4)$ & - \\
Distal anastomosis, median (IOR) & $150(140-165)$ & $321.67(300-330)$ & .38 \\
Total heparin dose (IU/kg), median (IOR) & $84(75-100)$ & $324(300-340)$ & .0001 \\
Total protamine dose (mg), median (IOR) & $250(245-260)$ & $400(380-430)$ & .0001 \\
Maximum ACT (s), median (IOR) & & .0001 &
\end{tabular}

$O P C A B$, Off-pump coronary artery bypass surgery; $O N C A B$, on-pump coronary artery bypass surgery; IQR, interquartile range.

TABLE 3. Clinical outcomes of patients

\begin{tabular}{|c|c|c|c|}
\hline Clinical outcomes & OPCAB group & ONCAB group & $P$ value \\
\hline Death & 1 & 0 & NS \\
\hline Myocardial infarction & 0 & 0 & NS \\
\hline Stroke & 0 & 0 & NS \\
\hline Postoperative blood loss at $2 \mathrm{~h}(\mathrm{~mL})$, median (IOR) & $130(100-180)$ & $250(230-300)$ & $<.01$ \\
\hline Blood transfusions (U), median (IOR) & $1(0.5-2)$ & $1.8(1-2)$ & NS \\
\hline Fresh frozen plasma (U), median & 0 & 3 & .42 \\
\hline Platelet transfusions (U), median & 0 & 0 & NS \\
\hline LOS in ICU (d), median (IOR) & $1(1-2)$ & $1.5(1-2)$ & NS \\
\hline LOS in hospital (d), median (IOR) & $6(5-8)$ & $7(6-8)$ & NS \\
\hline Hemoglobin at discharge $(\mathrm{g} / \mathrm{dL})$, median (IQR) & $11.5(10.0-12.2)$ & $11.6(10.5-12.5)$ & NS \\
\hline
\end{tabular}

$O P C A B$, Off-pump coronary artery bypass surgery; $O N C A B$, on-pump coronary artery bypass surgery; IOR, interquartile range; LOS, length of stay.

periods, respectively. Of note, there was a significant reduction in platelet count and an increase in P-selectin- and Annexin V-positive platelets after the operation in the OPCAB group. However, these changes did not significantly affect bleeding time or ADP-induced platelet aggregation in patients undergoing OPCAB after the procedure. Similarly, a postoperative decrease in platelet count and an increase in P-selectin and Annexin V-positive platelets were observed among patients undergoing on-pump surgery. These changes (both absolute and percentage change from baseline) in the ONCAB group were more pronounced compared with those in the OPCAB group (Table 5 and Figure 1). Additionally, a significant increase in the bleeding time and a decrease in ADP-induced platelet function were also observed in the ONCAB group.

Finally, there was no statistically significant relationship between preoperative versus postoperative changes in ADPinduced platelet aggregation and perioperative volume of blood loss $(R=0.45, P=.23)$. Similarly, no significant relationship was noted between changes in the preoperative versus postoperative P-selectin- and Annexin V-positive platelets and perioperative blood loss $(R=0.34$ and $R=$ $0.47, P=.18$ and $P=.31$, respectively).

\section{Discussion}

In this study we confirmed the previously reported postoperative decrease in platelet count, as well as activation of platelets, in patients undergoing ONCAB. ${ }^{12} \mathrm{We}$ noted an increase in P-selectin- and Annexin V-positive platelets and also a decrease in ADP-induced platelet aggregation. These changes in platelet count and function were associated with a significant increase in bleeding time. Directionally similar postoperative changes, although less marked, were observed in the OPCAB group, with a reduction in platelet count and an increase in the markers of platelet activation, such as P-selectin and Annexin V positivity. However, unlike those in the ONCAB group, these changes denoting platelet function were not associated with either an increase in bleeding time or a decrease in ADP-induced platelet aggregation.

Thrombocytopenia has been well documented in patients undergoing on-pump surgery and has been attributed to many factors, including hemodilution, mechanical disruption, adhesion to the extracorporeal circuit, and sequestration in organs. ${ }^{13}$ Additionally, platelet dysfunction has also been shown to occur during on-pump surgery, resulting both in the prolongation of the bleeding time and the decrease in ADP-induced platelet aggregation. Similarly, prior investigators have attested to platelet activation after use of cardiopulmonary bypass. ${ }^{14}$ Although there is a lack of consensus as to the pathophysiology of platelet activation, many potential explanations have been entertained. Notable among these are exposure to synthetic material of the extracorporeal circuits, generation of thrombin, and use of 
TABLE 4. Preoperative and postoperative platelet studies in patients undergoing OPCAB and ONCAB

\begin{tabular}{|c|c|c|c|c|c|c|c|}
\hline & $\begin{array}{l}\text { Preoperative } \\
\text { OPCAB }\end{array}$ & $\begin{array}{l}\text { Preoperative } \\
\text { ONCAB }\end{array}$ & $\begin{array}{c}P \\
\text { value }\end{array}$ & $\begin{array}{c}2 \mathrm{~h} \\
\text { postoperative } \\
\text { ОРСАВ }\end{array}$ & $\begin{array}{c}P \text { value vs } \\
\text { preoperative } \\
\text { OРCAB }\end{array}$ & $\begin{array}{c}2 \mathrm{~h} \\
\text { postoperative } \\
\text { ONCAB }\end{array}$ & $\begin{array}{c}P \text { value } \\
\text { vs } \\
\text { preoperative } \\
\text { ONCAB }\end{array}$ \\
\hline $\begin{array}{l}\text { Bleeding time (min), } \Delta \% \text { median } \\
\quad(\text { IQR) }\end{array}$ & $2.0(1.8-2.3)$ & $2.0(1.8-2.2)$ & 1.00 & $1.9(1.7-2.0)$ & .37 & $3.3(2.9-3.6)$ & .0001 \\
\hline $\begin{array}{l}\text { Platelet count }\left(\times 10^{3} / \mu \mathrm{L}\right), \Delta \% \\
\quad \text { median (IQR) }\end{array}$ & $262(230-284)$ & $285.6(248-293)$ & .73 & $183.8(172-193)$ & .0001 & $155.6(143-167)$ & .0001 \\
\hline $\begin{array}{l}\text { Mean platelet volume (fl), } \Delta \% \\
\text { median (IOR) }\end{array}$ & $7.8(7.7-8.0)$ & $7.7(7.6-8.0)$ & .28 & $8.1(7.9-8.2)$ & .2 & $8.1(7.9-8.2)$ & .36 \\
\hline $\begin{array}{l}\text { ADP aggregation (\%), } \Delta \% \text { median } \\
\text { (IQR) }\end{array}$ & $61.6(58-63)$ & $60.9(57-64)$ & .46 & $60.8(57-62)$ & .42 & $50.0(47-53)$ & .0001 \\
\hline $\begin{array}{l}\text { P-selectin-positive platelets (\%), } \Delta \\
\% \text { median (IOR) }\end{array}$ & $5.3(4.7-5.6)$ & $5.2(4.7-5.5)$ & .60 & $11.3(9-13.7)$ & .0001 & $14.3(13-15.2)$ & .0001 \\
\hline $\begin{array}{l}\text { Annexin V-positive platelets (\%), } \Delta \\
\% \text { median (IOR) }\end{array}$ & $0.77(0.5-0.9)$ & $0.72(0.5-0.88)$ & .43 & $2.5(1.3-3.4)$ & .0001 & $4.4(3.5-4.9)$ & .0001 \\
\hline
\end{tabular}

$O P C A B$, Off-pump coronary artery bypass surgery; $O N C A B$, on-pump coronary artery bypass surgery; IQR, interquartile range; $A D P$, adenosine diphosphate.

TABLE 5. Changes in platelet studies between the OPCAB and ONCAB groups

\begin{tabular}{|c|c|c|c|}
\hline & ОРСАВ group & ONCAB group & $\begin{array}{l}P \text { value for differences } \\
\text { between the } 2 \text { groups }\end{array}$ \\
\hline Bleeding time (min), $\Delta \%$ median (IOR) & $-5(0$ to -8$)$ & +60 (40 to 75$)$ & .0001 \\
\hline Platelet count, $\left(\times 10^{3} / \mu \mathrm{L}\right), \Delta \%$ median (IQR) & $-30(-25$ to -33$)$ & $-40(-35-$ to -43$)$ & .002 \\
\hline Mean platelet volume (fl), $\Delta \%$ median (IOR) & $+3(2$ to 4$)$ & $+5(2$ to 6$)$ & .20 \\
\hline ADP aggregation ( $\%), \Delta \%$ median (IQR) & $-1.29(0$ to -3$)$ & $-17(14.3$ to 20$)$ & .0001 \\
\hline P-selectin-positive platelets (\%), $\Delta \%$ median (IOR) & +113 (90 to 128$)$ & +175 (150 to 205$)$ & .003 \\
\hline Annexin V-positive platelets (\%), $\Delta \%$ median (IQR) & +212 (182 to 230$)$ & +528 (478 to 555$)$ & .0001 \\
\hline
\end{tabular}

$O P C A B$, Off-pump coronary artery bypass surgery; $O N C A B$, on-pump coronary artery bypass surgery; IQR, interquartile range; $A D P$, adenosine diphosphate.

heparin and protamine. ${ }^{15-17}$ These decreases in platelet counts and abnormalities of platelet function and activity have been implicated by many not only in the bleeding complications in the postoperative period but also in the thrombotic events (ie, recurrent ischemic events and type I and II neurologic injuries). ${ }^{18-21}$ The fact that these changes were less pronounced in the OPCAB group compared with in the ONCAB group attests to the relatively "preserved hemostasis" in the former group compared with the latter cohort and could potentially account for some of the differences in clinical outcomes between these 2 techniques reported previously.

Our findings should be viewed in light of previously published studies that evaluated hemostatic profile after OPCAB. Englberger and colleagues ${ }^{22}$ reported significantly lower values of fibrin monomer, thrombinantithrombin complex, and D-dimer values in patients undergoing $\mathrm{OPCAB}$ compared with those in the ONCAB group, reflecting preserved coagulant and fibrinolytic activity. Lo and associates ${ }^{23}$ found a significantly less pronounced activation of coagulation and fibrinolysis in the $\mathrm{OPCAB}$ group compared with that seen in the ONCAB group in the immediate postoperative period. However, there was a delayed postoperative response in the OPCAB group, leading to a delayed increase (20-96 hours) in these variables and resulting in no differences in these values at a later time point. Similarly, Czerny and coworkers ${ }^{24}$ found that in the early postoperative period the levels of interleukin 10, intercellular adhesion molecule 1 , and P-selectin were all lower in patients undergoing OPCAB than in patients undergoing ONCAB. However, these values were similar thereafter between the 2 groups beyond 4 hours after surgical intervention. Other investigators have shown similar lesser changes in platelet function after OPCAB in the immediate postoperative period compared with values seen after ONCAB surgery. ${ }^{25-27}$ Our findings are consistent with these studies, and our data indicate a lesser influence of $\mathrm{OPCAB}$ compared with $\mathrm{ONCAB}$ on platelet function in the immediate postoperative period, supporting the concept of greater preservation of hemostatic mechanisms with the former technique. In contrast, Parolari and associates ${ }^{28}$ found no differences in the postoperative tissue factor and P-selectin expression between patients in the OPCAB and ONCAB groups in the first month after CABG. The differ- 


\section{HRS postoperative \% changes in platelet Studies between studied groups}

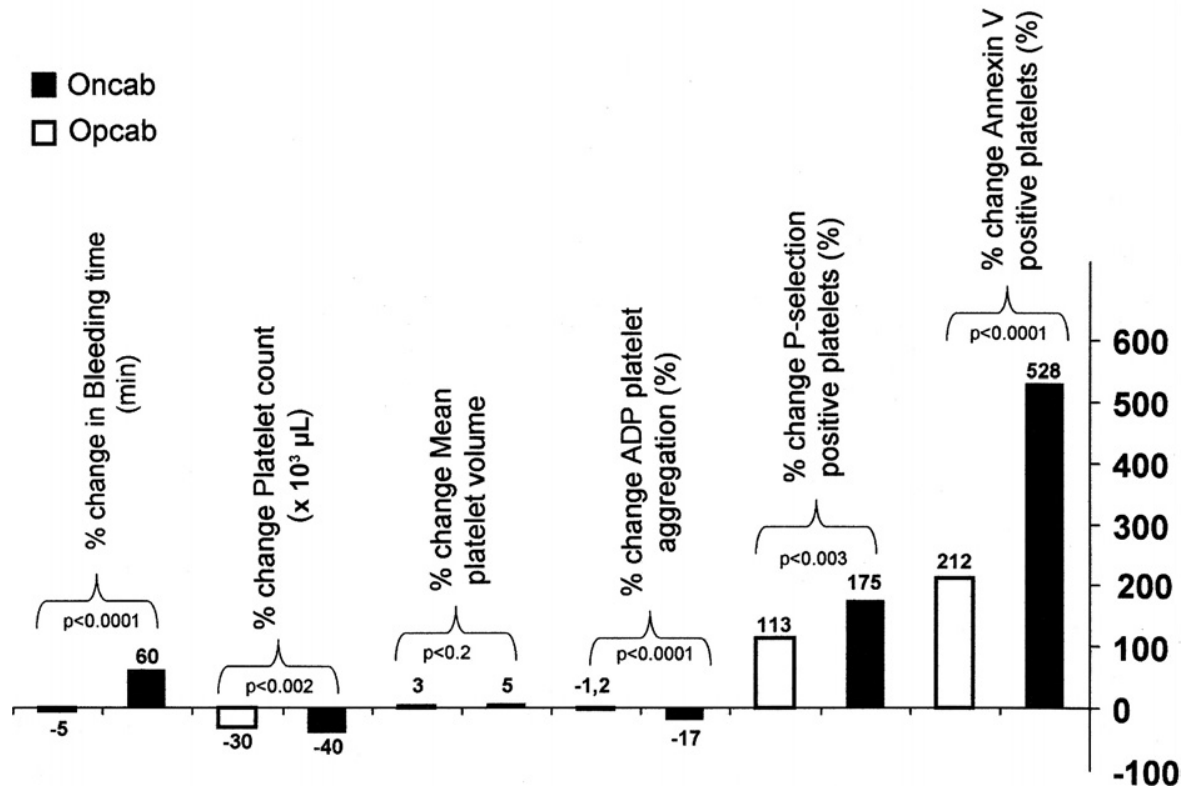

Figure 1. Off-pump (OPCAB) compared with on-pump (ONCAB) coronary artery bypass surgery. Differences in the percentage changes in postoperative platelet study values compared with preoperative values are shown. ADP, Adenosine diphosphate.

ent timings in the above studies for the measurement of coagulation, platelet function, and fibrinolytic activity might explain some of the differences noted in these studies.

We are unable to determine the exact cause for these changes, but we can speculate on some potential reasons. It is likely that platelet activation might be attributed to the overall hemostatic response to promote healing of surgical wounds and to inflammation that accompanies surgical intervention. Alternatively, contribution of heparin and protamine to some degree cannot be entirely excluded. Although future studies are needed to determine why these changes occur despite a lack of cardiopulmonary bypass, it is likely that the potential for less bleeding, as well as for a preserved hemostatic state, might explain some of the clinical differences in outcomes between the 2 techniques. ${ }^{6,8-11,21}$

Finally, the lack of a significant relationship between preoperative versus postoperative changes in ADP-induced platelet aggregation and $\mathrm{P}$-selectin- and Annexin V-positive platelets might be related to the small number of patient studies. Alternatively, given that flow cytometry is an extremely sensitive method for monitoring platelets, our data indicate that platelet function needs to be considered in light of other factors that promote hemostasis, and overall bleeding in the perioperative period is the sum of this multitude of factors that affect hemostasis rather than platelet function alone. Clearly, additional studies in a large number of patients might help provide additional insight into these factors.

\section{Study Limitations}

Our study involves a small number of patients, and these findings need to be confirmed in future studies in a larger number of patients. Additionally, this was a hypothesisgenerating study, and inferences regarding cause-and-effect relationship (particularly with regard to changes in platelet function and its influence on clinical outcomes) should be made with caution. We focused on early platelet function after surgical intervention. As such, inferences cannot be made regarding platelet function abnormalities beyond this time period. The inherent variation in heparin and protamine regimen in the 2 revascularization strategies might have had an influence on the differences in platelet function seen in the 2 groups. Nonetheless, our goal was to access the overall effects of the 2 approaches to $\mathrm{CABG}$ on platelet function rather than the individual influence of the procedures and different heparin/protamine dosing on platelet function. Thus our findings and inferences are appropriate when viewed in this context.

\section{Conclusions}

Compared with patients undergoing ONCAB, an early postoperative decrease in platelet count and increase in platelet activation occurs to a much lesser extent and does not alter bleeding time or ADP-induced platelet aggregation in patients undergoing OPCAB. This lack of significant effects on platelets might in part account for the potential decreased 
risk in bleeding and for preserved hemostasis seen in patients undergoing OPCAB compared with ONCAB. Future investigations in a large number of patients are needed to confirm these preliminary observations, as well as to determine the implications of these findings on clinical outcomes of patients undergoing $\mathrm{OPCAB}$ and $\mathrm{ONCAB} .{ }^{18-21}$

\section{References}

1. Despotis GJ, Goodnough LT. Management approaches to platelet related microvascular bleeding in cardiothoracic surgery. Ann Thorac Surg. 2000;70(suppl):S20-32.

2. Kestin AS, Valeri CR, Khuri SF, Loscalzo J, Ellis PA, MacGregor H, et al. The platelet function defect of cardiopulmonary bypass. Blood. 1993;82:107-17.

3. Maquellin KN, Berckmans RJ, Nieuwland R, Schaap MCI, Have KT, Eijsman L, et al. Disappearance of glycoprotein IB from the platelet surface in pericardial blood during cardiopulmonary bypass. J Thorac Cardiovasc Surg. 1998;115:1160-5.

4. Weerasinghe A, Taylor KM. The platelet in cardiopulmonary bypass. Ann Thorac Surg. 1998;66:2145-52.

5. Khuri SF, Wolfe JA, Josa M, Axford TC, Szymanski I, Assousa S, et al. Hematologic changes during and after cardiopulmonary bypass and their relationship to the bleeding time and nonsurgical blood loss. J Thorac Cardiovasc Surg. 1992;104:94-102.

6. Casati V, Gerli C, Franco A, Valle PD, Benussi S, Alfieri O, et al. Activation of coagulation and fibrinolysis during coronary surgery: on-pump versus off-pump techniques. Anesthesiology. 2001;95: 1103-9.

7. Van Dijk DV, Nierich AP, Jansen EW, Nathoe HM, Suyker WJ, Diephuis JC, et al. Early outcome after off-pump versus on-pump coronary bypass surgery: results from a randomized study. Circulation. 2001;104:1761-6.

8. Bull DA, Neumayer LA, Stringham JC, Meldrum P, Affleck DG, Karwande SV. Coronary artery bypass grafting with cardiopulmonary bypass versus off-pump cardiopulmonary bypass grafting: Does eliminating the pump reduce morbidity and cost. Ann Thorac Surg. 2001; $71: 170-3$.

9. Czerny M, Baumer H, Kilo J, Zuckermann A, Grubhofer G, Chevtchik $\mathrm{O}$, et al. Complete revascularization in coronary artery bypass grafting with and without cardiopulmonary bypass. Ann Thorac Surg. 2001; 71:165-9.

10. Cartier R, Robitaille D. Thrombotic complications in beating heart operations. J Thorac Cardiovasc Surg. 2001;121:920-2.

11. Mariani MA, Gu YJ, Boonstra PW, Grandjean JG, Oeveren WV, Ebels T. Procoagulant activity after Off-pump coronary operation: is the current anticoagulation adequate? Ann Thorac Surg. 1999;67:1370-5.

12. Ray MJ, Hawson GA, McLachlan G, O'Brien M. Relationship of platelet aggregation to bleeding after cardiopulmonary bypass. Ann Thorac Surg. 1994;57:981-6.
13. Muriithi EW, Belcher PR, Day SP, Menys VC, Wheatley DJ. Heparininduced platelet dysfunction and cardiopulmonary bypass. Ann Thorac Surg. 2000;69:1827-32.

14. Muriithi EW, Belcher PR, Rao JN, Chaudhry MA, Nicol D, Wheatley DJ. The effects of heparin and extracorporeal circulation on platelet counts and platelet microaggregation during cardiopulmonary bypass. J Thorac Cardiovasc Surg. 2000;120:538-43.

15. Khuri SF, Valeri CR, Loscalzo J, Weinstein MJ, Birjiniuk V, Healey NA, et al. Heparin causes platelet dysfunction and induces fibrinolysis before cardiopulmonary bypass. Ann Thorac Surg. 1995;60:1008-14

16. Li N, Astudillo R, Ivert T, Hjemdahl P. Biphasic pro-thrombotic and inflammatory responses after coronary artery bypass surgery. $J$ Thromb Haemost. 2003;1:470-6.

17. Tzima E, Walker JH. Platelet Annexin V: the ins and outs. Platelets. 2000;11:245-51.

18. Park Y, Schoene N, Harris W. Mean platelet volume as an indicator of platelet activation: methodological issues. Platelets. 2002;13:301-6.

19. Lumadue JA, Lanzkron SM, Kennedy SD, Kuhl DT, Kickler TS Cytokine induction of platelet activation. Am J Clin Pathol. 1996;106: 795-8.

20. Lund O, Christensen J, Holme S, Fruergaard K, Olesen A, Kassis E, et al. On-pump versus Off-pump coronary artery bypass: independent risk factors and off-pump graft patency. Eur J Cardiothorac Surg. 2001;20:901-7.

21. Manchio JV, Gu J, Romar L, Brown J, Gammie J, Pierson RN 3rd, et al. Disruption of graft endothelium correlates with early failure after off-pump coronary artery bypass surgery. Ann Thorac Surg. 2005;79:1991-8.

22. Englberger L, Immer FF, Eckstein FS, Berdat PA, Haeberli A, Carrel TP. Off pump coronary artery by-pass operation does not increase procoagulant and fibrinolytic activity: preliminary results. Ann Thorac Surg. 2004;77:1560-6.

23. Lo B, Fijnher R, Castigliego D, Borst C, Kalmann CJ, Nierich AP. Activation of hemostasis after coronary artery bypass grafting with or without cardiopulmonary bypass. Anesth Analg. 2004;99:634-40.

24. Czerny M, Baumer H, Kilo J, Lassnigg A, Hamwi A, Vukovich T, et al. Inflammatory response and myocardial injury following coronary artery bypass grafting with or without cardiopulmonary bypass. Eur J Cardiothorac Surg. 2000;17:737-42.

25. Bidstrup BP, Scarro H, Luque M. Platelet function after off pump surgery. Heart Surg Forum. 2003;6:286-7.

26. Poston R, Gu J, Manchio J, Lee A, Brown J, Gammie J, et al. Platelet function tests predict bleeding and thrombotic events after off pump coronary bypass grafting. Eur J Cardiothorac Surg. 2005;27:584-91.

27. Gerrah R, Snir E, Brill A, Varon D. Platelet function changes as monitored by cone and platelet analyzer during beating heart surgery. Heart Surg Forum. 2004;7:E191-5.

28. Parolari A, Mussoni L, Frigerio M, Naliato M, Alamanni F, Polvani $\mathrm{GL}$, et al. The role of tissue factor and P-selectin in the procoagulant response that occurs in the first month after on-pump and off-pump coronary artery bypass grafting. J Thorac Cardiovasc Surg. 2005;130: 1561-6. 